\title{
Luis Jimena Quesada, Devaluación y blindaje del Estado social y democrático de derecho, Editorial Tirant lo Blanch, Valencia, 2017, 100 pp., ISBN 9788491199960.
}

\author{
http://dx.doi.org/10.18543/ed-67(2)-2019pp397-405
}

1. El dominio que el autor presenta de los derechos sociales se constata perfectamente en la obra, al asumir un encaje práctico. Por ende, se confirma de manera impecable en la obra, su experiencia como miembro en la $\mathrm{Eu}$ ropean Social Charter Academic Network del Consejo de Europa y en el ejercicio como miembro del Comité Europeo de Derechos Sociales del Consejo de Europa. Habiendo sido parte activa en el contexto doctrinal europeo.

Desde su trabajo, el autor ofrece una visión sobre el Estado social presente. En esta línea, se percibe una crítica a la gestión de la crisis y la aplicación flexible de los estándares sociales en legislación y jurisprudencia. Todo ello, en un escenario de austeridad económica que parece que hemos tolerado, en particular en relación con las ramas que comprenden el Derecho Laboral, el Derecho Tributario y el Derecho Civil. El argumento escogido señala a un proceso de devaluación de la fórmula presente en nuestra Carta Magna del Estado social y democrático de derecho, en cierto modo, con un traspaso de parámetros normativos y jurisprudenciales que parecen obviar determinados mandatos constitucionales de asunción de los cánones europeos sobre derechos fundamentales ${ }^{1}$.

En el mismo prólogo, el profesor Terol Becerra evoca de manera acertada que «el Estado de Derecho representa un estándar de nuestros días», así, está señalando la hipótesis a resolver por él autor. Con otras palabras, si «el derecho debe resolver o no esta cuestión, que pugna con la economía y las finanzas».

El libro se articula en un prólogo, ocho capítulos y un epílogo. Asimismo

${ }^{1}$ «La traducción jurídica del proceso de deconstitucionalización es la desnormativización constitucional, la perdida de normatividad en el núcleo de la constitución, específicamente respecto al Estado social y sus materializaciones en el Texto fundamental. Desnormativización como pérdida de la prescriptividad de la norma constitucional, como incapacidad para presidir el ordenamiento y vincular a los poderes público», en MAESTRO BUELGA, G. (2017). El Estado social 40 años después: La deconstitucionalización del programa constitucional. Revista de Derecho Politico. UNED, septiembre-diciembre, pp.772-773. 
puede agruparse aquí a efectos explicativos en: una introducción que expresa la acentuación de la crisis económica al Estado Social; unos capítulos que recogen la concreta quiebra y sustracción de los principios constitucionales en nuestro Estado Social y Democrático de Derecho; y otros, que aluden la revelación de determinada jurisprudencia flexible o devaluada en el contexto anticrisis.

2. A manera de introducción, se recuerda la trascendental fórmula del artículo 1.1 de la Constitución siendo uno de «los principios por antonomasia de nuestro sistema constitucional»», o en otros términos, la calificación de norma fundamental o «metavalor absoluto», al contener la esencia constitucional. Desde esta base, toda legislación o jurisprudencia no debería articularse de manera flexible, sino al contrario, la producción normativa y jurisprudencial, sea o no en momentos coyunturales, debe cumplir los cánones impuestos de la fórmula del Estado social y democrático de derecho. Por ende, se advierte la necesidad de la construcción de un blindaje del Estado social, que inexorablemente tenga presente los valores superiores europeos e internacionales.

Tal como expone el autor, la crisis ha servido de pretexto en detrimento de la estabilidad jurídica para confeccionar «una legislación de urgencia y en una jurisprudencia coyuntural». En este panorama, se produce una legislación depreciada tanto en términos cuantitativos como cualitativos, proliferando así normas con una difícil articulación al sistema de fuentes y no adecuadas a normas o valores superiores, así como, en consecuencia, una devaluación jurisprudencial.
Respecto a ello, la legislación «anticrisis» no se ha visto equilibrada mediante jurisprudencia «compensatoria», antes al contrario, tal como se detalla en la obra, si corroborada por una especie de jurisprudencia en interés de ley anticrisis y, correlativamente, en desinterés constitucional o en desinterés europeo.

En referencia a los apartados que dilucidan sobre la quiebra de determinados principios constitucionales, distingue, como se ha dicho, el ámbito del Derecho Tributario, Derecho laboral y el Derecho Civil.

En primer lugar, en relación con el orden tributario, hace un análisis exhaustivo de la STS de 19 de noviembre de 2012, de la Sala de lo ContenciosoAdministrativo (STS 7933/2012), donde se estima el recurso de casación en interés de ley. El autor, al examinar la ponderación de los hechos, asiente una discrepancia a la resolución mayoritaria; puesto que considera que la opinión acertada sería la de los votos particulares que se produjeron. Cuestionando el trasfondo de sacrificio de garantías del administrado justiciable, al prevalecer de manera condescendiente una especie de sentencia «anticrisis» perseguidora del fraude fiscal sin atender a derechos de los administrados y justiciables. La Administración General del Estado mediante escrito presentado el 28 de Febrero de 2011 interpuso recurso de casación en interés de la ley, por considerar errónea y gravemente perjudicial para el interés general la doctrina contenida en la resolución recurrida, en concreto la sentencia de 27 de octubre de 2010 , Sección $3^{\circ}$, dictada por la Sala de lo Contencioso Administrativo del TSJ 
de la Comunidad Valenciana. Todo tiene su origen en la liquidación por el Impuesto de Sociedades, ejercicios 1992 y 1993 y la sanción correlativa a una Clínica dental. Como bien sabemos, el recurso de casación en interés de la Ley es de naturaleza excepcional, a modo de remedio especial y último del que disponen las Administraciones Públicas para evitar que sentencias que se estimen erróneas y que puedan comprometer y dañar gravemente el interés general más allá del caso resuelto definitivamente por las mismas perpetúen o multipliquen en el futuro sus efectos negativos ante la posibilidad de la repetición o reiteración de su desviada doctrina. Pues bien, en línea de los votos particulares, sobre la eficacia o no interruptiva del acto anulado, o la diferenciación entre interrupción o suspensión de la prescripción; el autor de la obra, considera que «la problemática no cabe contraerla a una mera cuestión procesal y de estricta legalidad ordinaria...pues cabalmente nos hallamos... ante un prevalente problema de fondo de salvaguardia de derechos fundamentales». Debido a ello, la interrupción o suspensión de liquidaciones tributarias se encuadraría en plazos excesivos. Se propone una mayor voluntad jurisprudencial para que impere una mayor coherencia con mandatos constitucionales y europeos. Posteriormente extrae una valoración razonada de cómo los dictados de la eficacia y eficiencia administrativa que orientan el cumplimiento de obligaciones tributarias (traducido en recursos) no deben ignorar las garantías de los derechos fundamentales en juego.

En segundo lugar, en lo que menciona al orden laboral, a propósito del
ATS de 4 de noviembre de 2015 de la Sala Social del Tribunal Supremo (ATS 10135/2015), declarando la inadmisión del recurso de casación para la unificación de doctrina. En este supuesto se interpuso recurso de casación para la unificación de doctrina contra la sentencia de la Sala de lo Social del TSJ de Cataluña de 2 de diciembre de 2014, por entender que un despido era improcedente. Tal como infiere el autor, en los motivos casacionales, parece que el Auto se aleja de los cánones jurisprudenciales europeos recientes, establecidos por el Comité Europeo de Derechos Sociales, produciéndose una especie de anomalía en el sistema de fuentes del Derecho del Trabajo. En esta línea propone evitar lo que viene en denominar como flexinormatividad, apelando por un cambio de criterio jurisprudencial evolutivo, a la luz de las fuentes constitucionales sociales internacionales. En definitiva, el autor aquí constata la tendencia involutiva de la Sala Social del Tribunal Supremo que descarta reiteradamente la jurisprudencia europea. De este modo, parece chocar frontalmente no sólo con los principios de un Estado social de derecho (art.1 CE), sino también con los principios de la Carta Social Europea -ratificada por España- y el Convenio ${ }^{\circ} 158$ de la OIT -igualmente ratificado- normas que garantizan protección al trabajador en caso de despido.

En último lugar, en lo que respecta al orden civil, escoge la STS de la Sala de lo Civil, $\mathrm{n}^{\circ} .139$ de 25 de marzo de 2015 (STS 1280/2015). En la referida Sentencia se resuelve la controversia en la que dos prestatarios demandaban 
a un banco la declaración de nulidad de la cláusula suelo del contrato de préstamo hipotecario con una justificación de limitación de la retroactividad de la declaración de nulidad (eficacia ex tunc), exceptuando la aplicación del artículo 1303 del Código Civil. Produciéndose, como se expone en el libro, un trastorno de la seguridad jurídica y del orden público económico, perjudicando de manera notoria a los consumidores. Una especie de ruptura del equilibrio entre liberalismo y democracia, restringiendo derechos fundamentales. Resulta curioso que se aparte de la regla clásica reiterada por la jurisprudencia civil del «quod nullum est nullum effectum producit» (nulo no produce ningún efecto). Tras la lectura de los votos particulares de los Magistrados discrepantes Orduña Moreno e O'Callaghan Muñoz se razonan estas consideraciones y otras, como el control de transparencia. En definitiva, esta discrepancia apunta a que parece razonado haber declarado abusiva por falta de transparencia real de las cláusulas objeto de examen y del pleno efecto devolutivo de las cantidades pagadas desde la perfección o celebración del contrato, dado que la nulidad de pleno derecho de la cláusula en cuestión determinó la carencia de título alguno que justifique la retención de las mismas y su atribución al predisponente.

3. En resumidas cuentas, la actualidad parece evidenciar una fuerte corriente tendente a aplicar la teoría y métodos económicos a la práctica jurídica, afirmándose que «ofrecen mejores posibilidades para una práctica legal justificada y coherente, hasta el punto de concebirla como una de las teorías dominantes de la jurisprudencia», cuando el análisis riguroso nos muestra otras posibilidades ${ }^{2}$.

En esta línea, al valorar el apartado del apartamiento de los estándares del Estado social de la jurisprudencia y la flexibilidad del acervo social, desarrolla una valoración en profundidad, analizando la legislación producida en el contexto de crisis económica. Trae a colación, la STC 8/2015, de 22 de enero, que desestima el recurso de constitucionalidad promovido contra distintas disposiciones de la Ley 3/2012 de medidas urgentes para la reforma laboral, al vulnerar varios preceptos constitucionales. En este punto, se apunta que, pese a reconocer en los fundamentos jurídicos del fallo la singular posición que ocupa los sindicatos en la configuración de nuestro Estado social y democrático de derecho, asimismo la referida sentencia alude que los derechos colectivos laborales institucionalizados por la Constitución (huelga, negociación y conflictos colectivos) no son exclusivos de los sindicatos. De este modo, el legislador goza de un amplio margen de libertad para delimitarlos, lo cual, a su vez, permite al Gobierno y

2 «Lo que nos interesa desde el punto de vista constitucional es señalar que no hay una única solución posible a la crisis y que, en la pretensión de reducir a una las respuestas a la crisis hay, desgraciadamente, una profunda actitud democrática que intenta apartar del terreno de la democracia pluralista la solución de los conflictos políticos», en BALAGUER CALLEJÓN, F. (2013). Crisis económica y crisis constitucional en Europa. Revista de Derecho Constitucional, núm.98, mayo-agosto, p.92. 
al Parlamento una concreta política económica y social, en atención a las circunstancias económicas y a las necesidades sociales. Jimena Quesada pone en valor el voto discrepante a la STC 8/2015, al criticar la jurisprudencia devaluada y anticrisis; igual sucede al analizar la STC 119/2014, por este y otros autores ${ }^{3}$. Deduciendo que existen limitaciones a los derechos sociales en un contexto de crisis económica, pero no por ello, cabe suprimir su contenido esencial o descartar su efectividad. Precisamente el auto reucuerda que el Comité Europeo de Derechos Sociales declaró en las Conclusiones sobre el cumplimiento en España de la Carta Social del año 2014 determinadas irregularidades formales de la Ley 3/2012, al no ser conformes al artículo 6.2 de la Carta Europea. En consecuencia, el Comité Europeo de Derechos Sociales declaró -sobre este aspecto- que se socavaban los fundamentos del Estado social. Si bien, en el procedimiento

3 «La banalización de la negociación colectiva, desconectándola del Estado social y la intervención promocional del trabajo que realiza la mayoría del Tribunal en la Sentencia 119/2014 es ejemplo del carácter disciplinante del ordenamiento de la UE. La contraposición entre constitución y reforma laboral viene reconocida por parte de algunos integrantes del tribunal (véanse el voto particular de F.Valdes Dal-Re al que adhieren A.Asua Batarrita y L.I Ortega Alvarez) que abre un flanco evidente a la crítica jurídica de la sentencia», en MAESTRO BUELGA, G. (2017). El Estado social 40 años después: La deconstitucionalización del programa constitucional. Revista de Derecho Político. $U N E D$, septiembre-diciembre, p.795. legislativo nacional se omitió este llamamiento al legislativo y ejecutivo en relación con lo prescrito en tratados internacionales.

Para el autor, este proceso devaluador es muy nítido: se origina con el asalto a los principios constitucionales del Estado social, favorecido posteriormente por la asunción de una jurisprudencia obsoleta, proyectándose en una preocupante flexibilidad del acervo social, a través, de un manejo incongruente de las fuentes constitucionales sociales de proyección internacional. Bastaría aludir, el ejemplo de la modalidad de contrato de trabajo por tiempo indefinido de apoyo a los emprendedores con período de prueba de un año y la inaplicación en la empresa de los convenios colectivos aplicables, para comprender la envergadura de estas medidas, y que parecen tomar una posición que casa poco con el modelo constitucional de relaciones laborales.

En el capítulo séptimo, el panorama presentado muestra determinadas medidas normativas y jurisprudenciales de austeridad muy particulares, encaminadas a recortar derechos sociales, bajo el pretexto de la contención del gasto y equilibrio presupuestario, minimizando los estándares de una democracia plural y real. En particular, por ejemplo, pone el foco en la Ley Orgánica 2/2014 de 21 de mayo, de reforma del Estatuto de Autonomía de Castilla-La Mancha, que como medida anticrisis rebajaba el número mínimo y máximo de diputados integrantes de las Cortes de la Comunidad Autónoma referenciada, en concreto de 25 a 35, en lugar de la anterior de 47 a 59 diputados. Pues bien, la STC 
197/2014 de 4 de diciembre, confirmó la legitimidad de la medida, al fallar que no vulneraba la proporcionalidad del artículo 125.1 de la Constitución Española, ni el pluralismo político ni el derecho de acceso a los cargos públicos en condiciones de igualdad (arts.1.1 y 23.2 CE). Como bien entiende el autor, se deja de valorar la proporcionalidad jurídico-constitucional de razonabilidad de esa medida, invocada por el texto del preámbu1o. Tras presentar numerosos contra-argumentos a la fundamentación jurídica de la sentencia, se destacan algunas aproximaciones críticas que nos permiten analizar con una mayor luz el problema. Por ejemplo, cuando habla de que «la regeneración democrática implica incidir más en incrementar la calidad que en reducir la cantidad», o cuando menciona «si la controvertida medida reductora del órgano decisor legislativo queda o no avalada desde la perspectiva de la teoría decisional de la democracia». Este horizonte acaba por mostrarse en el capítulo octavo, con el poco eco de los parámetros más favorables a la efectividad de los derechos sociales por parte de la jurisdicción y lo que puede determinar como una renuncia al «engranaje de tutela multinivel».

4. Estamos por tanto, ante una obra fundamental del profesor Jimena Quesada, abordando un tema que viene preocupando a la sociedad en su conjunto; más aún, especialmente de utilidad para reflexionar sobre la imposición de una legislación «anticrisis» validada por una "coherente» pero devaluada jurisprudencia. En este punto, la justicia constitucional como pieza esencial de cierre y guardián supremo de nuestra Carta Magna, parece descartar el complejo proceso hacia la efectividad real de los derechos fundamentales en un marco de defensa multinivel de éstos.

En su epílogo final muestra otra resolución con reflejo devaluador de la fórmula expuesta, infiriendo que los órganos constitucionales han desatendido los cánones europeos e internacionales y, en consecuencia, el respeto $y$ «el mandato interpretativo del artículo 10.2 en conexión con el mandato aplicativo impuesto por los artículos 93 a 96 de la Constitución»; luego, también considera que estos pronunciamientos confirman el abuso recurso a legislación excepcional o de urgencia, argumentados en base a una coyuntura de crisis económica. En consecuencia, resultando más nociva a las situaciones de precariedad o vulnerabilidad. A su juicio, se arrinconan los criterios de racionalidad y proporcionalidad que deben salvaguardar a los derechos fundamentales en juego. Por ende, se requiere voluntad de todos los ámbitos, para salvaguardar los pilares básicos de nuestro Estado social y democrático de derecho. Precisamente por ello, no será necesario obrar simples compensaciones parciales jurisprudenciales que dotan una efectividad más amplia.

En palabras del autor: «Si los principios y derechos constitucionales susceptibles de blindar y optimizar nuestro Estado social y democrático de derecho valen tanto como sus garantías, las garantías valen a su vez tanto como un ejercicio de voluntad positiva de asumir nuestras responsabilidades compartidas en la promoción y defensa de esos principios y derecho». 
Hay que reseñar que algunas conclusiones a las que llega el autor son compartidas y expuestas por otros/as autores de la doctrina. El optimismo previo a estos años, justo al comienzo de la coyuntura de crisis, vaticinó eficazmente la continuidad de esta economía social que aguarda un bienestar a la sociedad y corrige parcialmente al mercado ${ }^{4}$, no obstante, la economía de mercado ha profundizado expansivamente en lo que refiere a la justicia, pluralismo e igualdad; observándose como el discurso económico en esta coyuntura económica sufrida, y que aun padecemos, ha impuesto como únicas sus opciones, cerrando, de este modo, el cauce del pluralismo

4 «el sistema político seguirá siendo el Estado social y democrático de Derecho, que se ha reafirmado durante la crisis y seguirá siendo, al menos en Europa, la forma política que se suceda a sí misma. Lo primero porque el mercado desregulado ha provocado la crisis y se ha mostrado incapaz de hacerle frente, haciéndose evidente que también en la escasez debe haber equidad, igualdad, justicia, solidaridad y pluralismo. En la escasez más aún que en la abundancia, puesto que, si en tal circunstancia no puede hablarse propiamente de bienestar social y económico, sí se puede hablar de Estado social, uno de cuyos principales fines sigue siendo el bienestar, $y$, mientras se va alcanzando, procura que nadie caiga por debajo del mínimo existencial. Lo segundo porque es la forma política más ajustada a esa economía social de mercado parcialmente corregida», en TORRES DEL MORAL, A. (2010). Realización del estado social y constitución económica. En TEROL BECERRA, M.J (dir.). El Estado Social y sus exigencias Constitucionales (p.109). Tirant lo Blanch, Valencia. constitucional y desnaturalizando el sistema constitucional. La doctrina considera que esta línea de actuación en la coyuntura de crisis económica se aleja de una idónea actitud democrática, al descartar el pluralismo de ideas y soluciones en todo conflicto político; la función nuclear constitucional parece haberse visto obstaculizada. La concepción única y suprema en términos económicos permite deducir que la democracia es entendida como un producto $\mathrm{y}$, peor aún, es que la justificación excepcional y urgente de estas medidas probablemente se basa en numerosas falacias; por ejemplo, una es la atribución del excesivo gasto $\mathrm{y}$ deuda pública, ignorando que la deuda pública al surgir la crisis era inferior a la requerida como consecuencia de acudir a los mercados; y otra, al concluir con rotundidad, sin ningún tipo de valoración, una limitación de los gastos sociales como único factor para promocionar el equilibrio presupuestario, omitiendo la vía del aumento de ingresos públicos. Sin democracia pluralista no existe condición necesaria para que la Constitución resuelva problemas mediante el Derecho. El poder globalizado desenfrenado, la utilización de procedimientos informarles por parte de la Unión Europea incapaces de ofrecer respuestas y la especulación financiera como beneficiaria, entre otros hechos, presuntamente se están imponiendo en nuestras democracias, incluyendo la nuestra. Consideramos modestamente que para resolver todo conflicto se precisa la idea primordial del pluralismo, tal como se ha apuntado.

Fruto de esta afirmación material de Forma Global de Mercado, este 
proceso devaluador de la Constitución, la legislación y la jurisprudencia, lo que el profesor Maestro Buelga ha denominado deconstitucionalización y desnormativización, supone una ruptura de los contenidos del Estado social. La cláusula del Estado social recogida en el artículo 1.1 de la Constitución, se ha visto desnaturalizada, al trasladar sus efectos a la acción legislativa infraconstitucional ${ }^{5}$; derivando en una distorsión que el autor Jimena Quesada formula acertadamente como flexinormatividad. Permitiendo que la constitución económica relativice al Estado social, dado que los derechos sociales entre sus caracteres se definen como derechos débiles, al ser derechos distributivos y vinculados al conflicto social.

5 «la cláusula de Estado social como una cláusula finalista de escasa densidad jurídica y cuya eficacia depende de la materialización instrumental que realiza el conjunto del ordenamiento jurídico, que no es ajena al momento socio-económico real. Qué duda cabe que la sumisión del alcance del artículo 1.1 CE a las exigencias del momento y el traslado a la acción legislativa e infraconstitucional desnaturaliza el Estado social, posibilitando mantener su aportación legitimadora formal en un contexto de ruptura de la forma de Estado, anulando sus contenidos. Esta concepción permite obviar la desnormativización constitucional que las transformaciones, acaecidas en las últimas tres décadas han producido, sustituyéndola por una concepción infinitamente flexible de la Constitución», en MAESTRO BUELGA, G. (2017). El Estado social 40 años después: La deconstitucionalización del programa constitucional. Revista de Derecho Político.UNED, septiembre-diciembre, pp.774-775.
Por último, recordar que al constitucionalizar el equilibrio presupuestario hipotéticamente ha quebrado el equilibrio entre la dimensión garantista $\mathrm{y}$ conflictual de estos derechos.

Por último, evocamos que las Constituciones no sólo contribuyen a la obtención del bienestar ciudadano, sino que persiguen una dimensión social. Tras 40 años de la entrada en vigor de la Constitución Española de 1978, no parece exagerado sostener que ha sido un período fructífero en lo que se refiere a medidas normativas destinadas a la construcción social con una real superación de la inicial versión del proyecto liberal de la fórmula del Estado de derecho por un programa amplio proyectado en la receta del Estado social de derecho, y la de éste al mismo tiempo, por el Estado democrático de derecho. Confiriéndole a la fórmula de Estado social, un presupuesto innovador del principio básico de la formulación del Estado liberal, al entender que el orden de las sociedades no es algo dado natural; sino que se tiene que perfeccionar a través de la actuación estatal. Esta idea de Estado social significa la asunción por parte del poder público de redistribuir la riqueza y prestar determinadas prestaciones que exigen los derechos sociales.

En conclusión, en esta estupenda obra de Jimena Quesada -en línea con otros autores- deja entrever de manera ejemplificada con legislación y jurisprudencia ocasionada en el intervalo de crisis económica, como el Estado social se ha visto devaluado sin oportunidad de blindarlo. Precisando que la articulación legislativa y jurisprudencial mediante la adecuación a la norma 
constitucional, no debe conducir a una maleabilidad de la fórmula del artículo 1.1 CE. Sopesando con crítica constructiva lo que entiende como una devaluada jurisprudencia y legislación anticrisis. Junto a lo expresado, estimamos que parece inferir una concepción sesgada de la economía que permite, en cierto modo, una instrumentalización de los derechos sociales.

Amir Al Hasani Maturano

Profesor Ayudante Derecho Constitucional

Universidad de las Islas Baleares 


\title{
Luis Jimena QueSADA, Devaluación y blindaje del Estado social y democrático de derecho, Editorial Tirant lo Blanch, Valencia, 2017, 100 pp., ISBN 9788491199960.
}

\author{
http://dx.doi.org/10.18543/ed-67(2)-2019pp397-405
}

\section{Copyright}

Estudios de Deusto es una revista de acceso abierto, lo que significa que es de libre acceso en su in tegridad. Se permite su lectura, la búsqueda, descarga, distribución y reutilización legal en cualquier tipo de soporte sólo para fines no comerciales, sin la previa autorización del editor o el autor, siempre que la obra original sea debidamente citada y cualquier cambio en el original esté claramente indicado

Estudios de Deusto is an Open Access journal which means that it is free for full access, reading, search, download, distribution, and lawful reuse in any medium only for non-commercial purposes, without prior permission from the Publisher or the author; provided the original work is properly cited and any changes to the original are clearly indicated. 